\title{
Performance Evaluation of Pellets Forming Unit in Local Feed Pelleting Machine Abo-Habaga, M. M. ${ }^{1}$; A. F. Bahnassi ${ }^{2}$;T. H. EIShabrawy ${ }^{1}$ and Abeer W. ElHaddad ${ }^{2}$ ${ }^{1}$ Ag. Eng. Dept., Faculty of Ag., Mansoura University. \\ ${ }^{2}$ Ag. Eng. Res., Inst., (AEnRI), El-Giza, Egypt.
}

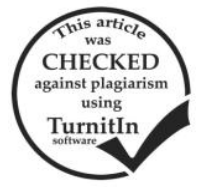

ABSTRACT

This study was carried out to manufacture and evaluate a small local feed pelleting machine. The experimental studies were confined to determine the effect of: die speed $(85,95,115,160 \& 190$ r.p.m.), die holes' diameter $(3,4 \& 5 \mathrm{~mm})$, moisture content of feed mixture (25, $28 \& 31 \%)$, adhesive material (without any, molasses \& gelatin) and different sources of power: (220V., AC, on grid system - Diesel generator - 1, 5 and 8 hours PV system). On some parameters of the study such as: productivity, pelleting efficiency, pellets durability, specific consumption energy and production cost. The experimental results showed that the highest value of pelleting machine productivity was $40.220 \mathrm{~kg} / \mathrm{h}$ at die speed $190 \mathrm{rpm} ., 5 \mathrm{~mm}$ die holes' diameter and $28 \%$ moisture content of feed mixture with gelatin as adhesive material in feed formula. At the same conditions, the pelleting efficiency was $98.082 \%$, pellets durability was $97.420 \%$, specific consumption energy was $15.08 \mathrm{~kW} . \mathrm{h} /$ ton and production cost was $39 \mathrm{LE} / \mathrm{ton}$.

\section{INTRODUCTION}

It is desirable to have the pelleting machine which can produce efficiently the pelleted roughage which has the hardness appropriate for feeding purpose, but not easily be collapsed during the handling, Susawa (1978). Fouda et al. (2015) mentioned that protein shortage in Egypt results from high prices of protein production lines especially those imported from abroad. Manufacturing local pelleting machines will serve to solve the problem and reduce the production cost in comparison to imported machines. Kaliyan and Morey (2009) concluded that feed moisture content, biomass constituents, feed particle size, feed conditioning temperature, added binders and densification equipment variables as process parameters all affect feed durability. Kaddour and Elmetwalli (2015) concluded that increasing roller speed from 155 to $215 \mathrm{rpm}$ with $10 \mathrm{~mm}$ teeth width increased pellet mill production rate from 370.3 to $383.9 \mathrm{~kg} / \mathrm{h}$. Increasing roller speed over $215 \mathrm{rpm}$ decreased the production rate. Highest pelleting efficiency of 98.6 was recorded at $230 \mathrm{rpm}$ rollers speed. At all tested feeding rate, pellets durability increased with increasing roller speed . David (2003) mentioned that understanding the terminology used to describe dies is important when choosing die specifications, different feed and ingredients require specific amounts of time in the die hole-die retention time to be bind together to form a pellet. Larger die working areas provide more retention time to form pellets, reduce power consumption per ton of feed pelleted and improve production efficiencies. Abdel wahab et al. (2011) Observed that the highest production rate of $151.8 \mathrm{~kg} / \mathrm{h}$ at real diameter of $4 \mathrm{~mm}$ increased to $187.2 \mathrm{~kg} / \mathrm{h}$ at real hole diameter of $5 \mathrm{~mm}$. Tabil and Sokhansanj (1996) mentioned that the durability of samples was generally better using the smaller die (higher (L/d ratio). Greer and Fairchild (1999) found that the moisture in feed mash affects pellets quality and production rates. Moisture in feed mash comes from two sources: bound moisture present in the feed ingredients and added moisture from water and steam addition. The moisture of cold feed entering the conditioner limits the amount of steam that can be added to the mash during conditioning. Tumuluru et al. (2011) found that increasing the moisture content of ingredient blends from 15 to $25 \%$ (w.b.) resulted in a $28.2 \%$ increase in durability. Tumuluru (2013) found that pellet moisture content decreased with increase in preheating temperature to about $110 \mathrm{c}$ and decreasing the feedstock moisture content to about $28 \%$ (w.b.). Tumuluru (2015) indicated that higher feed stock moisture content of $38 \%$ (w.b.) and a lower die speed of $2400 \mathrm{rpm}$. increased the specific energy consumption, whereas lower to medium preheating temperature (30-70c), medium feedstock moisture content of $33 \%$ (w.b.), and a higher die speed of $3600 \mathrm{rpm}$. minimized the specific energy consumption to $<100 \mathrm{kWh} / \mathrm{ton}$

The aim of this study is to manufacture and evaluate a small local pelleting machine for animal feed, operated by different power sources. Farmer and small breeder can obtain this machine, because of its small size and it works by very low energy by comparing with imported machines of animal feed manufacturing. It can be manufactured in modest workshops, and can be manufactured in large quantities to cover the local needs.

\section{MATERIALS AND METHODS}

The main parts of the pellets forming unit in the animal feed pelleting machine:

The pellets forming unit in the pelleting machine consists of conical feed hopper, pellets forming unit (two pressing rollers and flat die), the main shaft, reduction unit (bevel gear, 1: 2.75 and pulleys 1:4), frame and axial wheels, as shown in Figures (1, a, b and c). The machine was driven by electric motor (one phase) of $0.75 \mathrm{~kW}$, at 1440 r.p.m. through AC. $220 \mathrm{~V}$. On grid or diesel generator of $2.5 \mathrm{~kW}$, or electricity generated from photovoltaic panels of $1.2 \mathrm{~kW}$.

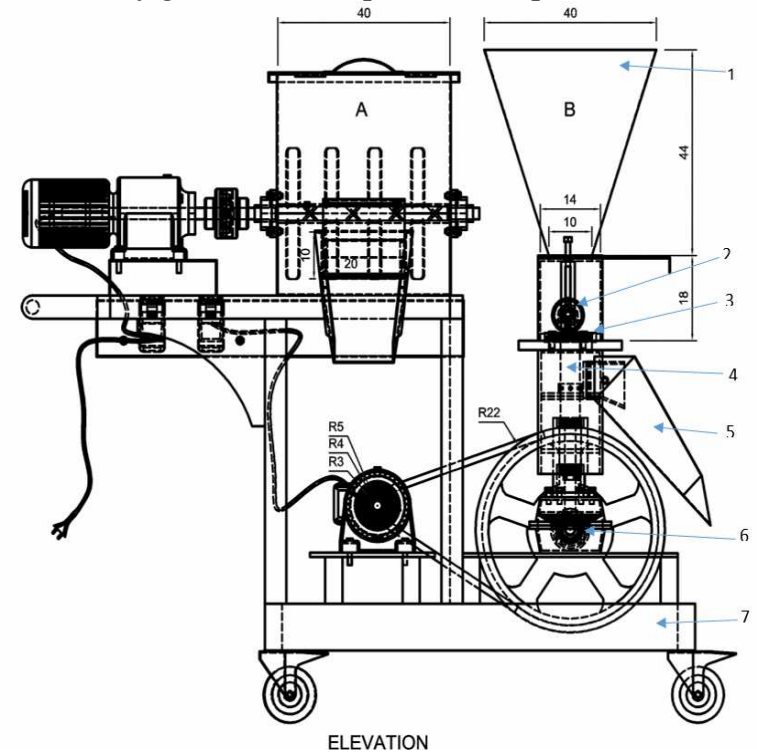

Figure 1. A schematic diagram of the pelleting machine.

A. Pellets Forming Unit in Pelleting Machine

1. Conical feed hopper. 2. Pressing rollers. 3. Die.

4. The main shaft. $\quad 5$. Outlet hall for pellets.

6. Reduction unit (bevel gear, 1: 2.75) 7. The frame. 
Table 1. Die hole-geometry:

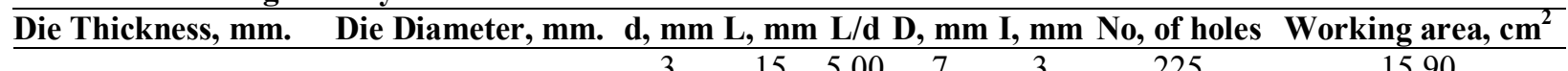

\begin{tabular}{|c|c|c|c|c|c|c|c|c|}
\hline \multirow{3}{*}{18} & \multirow{3}{*}{120} & 3 & 15 & 5.00 & 7 & 3 & 225 & 15.90 \\
\hline & & 4 & 15 & 3.75 & 8 & 3 & 176 & 22.12 \\
\hline & & 5 & 15 & 3.00 & 9 & 3 & 133 & 26.11 \\
\hline
\end{tabular}

$\mathrm{d}=$ die hole diameter, $\mathrm{L}=$ land length, $\mathrm{I}=$ cone height $\mathrm{and} \mathrm{D}=$ entry diameter.

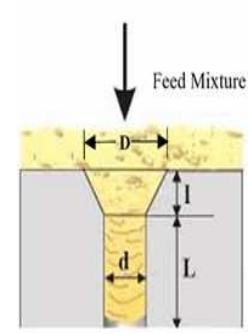

Fig. (a)

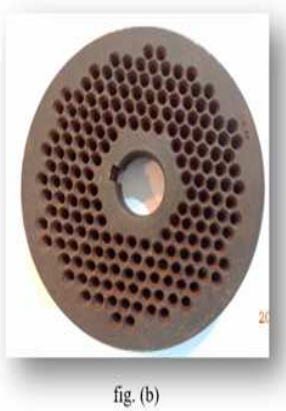

Fig. a. Die hole-geometry, fig.

b. Photographed of the die, fig

c. Photographed of the pellets forming unit

Percentages of components of the Rabbits Growth Feed used in this study: 20\%Corn Meal, 30\% Clover Hay, 28.13\% Wheat Bran, 13\% Soybean Meal, $3 \%$ Molasses, $1 \%$ Limestone, $0.3 \%$ Premix, $0.5 \%$ Sodium Chloride and $0.07 \%$ Methionine.

The experimental studies were confined to determine the effect of: Die speed $(85,95,115,160$ and190 r.p.m.), Die holes' diameter (3, 4 and $5 \mathrm{~mm}$ ), moisture content of feed mixture $(25,28$ and $31 \%) \&$ Adhesive material (without any, molasses \& gelatin) and different sources of power: $(220 \mathrm{~V} ., \mathrm{AC}$, on grid system - Diesel generator - 1-hour PV system - 5-hours PV system - 8-hours PV system).

On some parameters of the study such as:

1-Samples moisture content, \%: Electric oven was used to determine moisture content of feed mixture. The samples placed in the drying oven at $103^{\circ} \mathrm{C}$ for 24 hours and weighted after cooling.

The following equation used to determine the moisture content :

$\mathrm{Mc}\left(\mathrm{w}_{\mathrm{b}} \%\right)=\frac{\text { weight of wot rample-waight of dry rawple }}{\text { weight of wet rample }} \times 100--(1)$

Where: $\mathrm{Mc}(\mathrm{Wb} \%)=$ moisture content in wet basis, \% .

2-Productivity (capacity) $\mathrm{Kg} / \mathrm{h}$ :

The productivity of the machine was measured as the mass of pellet collected per hour. During the experiments the compressed pellets were collected for every 60 seconds and productivity was calculated as follows:

Productivity $(\mathrm{Kg} / \mathrm{h})=(\mathrm{Wp} / \mathrm{T})$

Where: Wp: pellets mass (kg). T: Consumed time (h.).

3-Pelleting efficiency, \%: was calculated according to (Abdel Wahab et al., 2011).

Pelleting efficiency $(\%)=(\mathrm{Wp} / \mathrm{Wm}) \times \mathbf{1 0 0}$

Where: Wp : pellets mass (g). Wm : feed mixture mass (g).

4-Pellets durability, \%: a durability (tumbling box) tester was manufactured by the author according to American Society of Association Executives (ASAE Standard, 1996).

Durability $(\%)=W a / W b \times 100$

Where: Wa : pellets mass after tumbling (g) . $\mathrm{Wb}$ : pellets mass before tumbling $(\mathrm{g})$
5-Specific consumption energy, $\mathbf{k W} . \mathbf{h} / \mathbf{k g}$ : Multimeter was used for measuring current strength and potential difference, respectively before and during experiments. Readings of ampere (I) and volt (V) were taken before and during each treatment.

Consumed power, $P=(I \times V \times \cos \theta) / 1000, k W----(5)$

Where: I : Line current strength, Amperes.

$\mathrm{V}$ : Potential difference, Volts. $\operatorname{Cos} \theta$ : Power factor, equal 0.76.

Specific consumption energy $(\mathbf{k W} \cdot \mathbf{h} / \mathbf{k g})=$ (consumed power $(\mathrm{kW})) /($ machine productivity $(\mathrm{kg} / \mathrm{h}))--(6)$

6-Costs:

Fixed costs:

- Depreciation (Dep.): Declining balance method employed in calculating depreciation (Barger et al, 1979). The relationships are as follows:

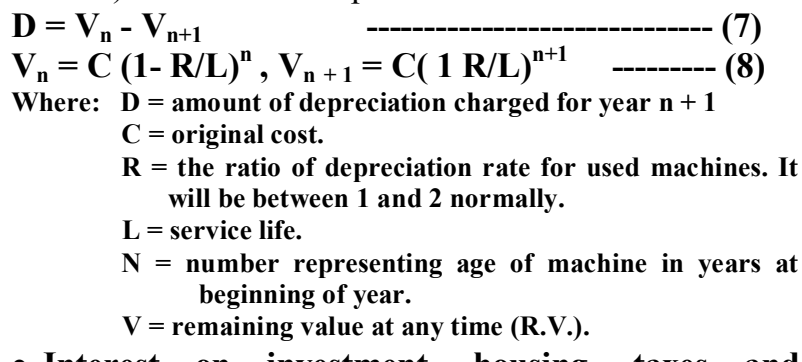

- Interest on investment, housing, taxes and insurance, (IHTI): It was estimated $13.8 \%$ of the remaining value (Barger et al., 1979).

Operation costs (Variable costs):

- Repairs and maintenance ( $R$ and $M)$ : Repair costs are very high in developing countries and contribute significantly to the total cost. It was estimated $50 \%$ of the initial value, spread over the life of the machine, has been taken (Kaul and Egbo, 1985).

- Lubrication costs for a machine are equal to10\% of fuel cost (Barger et al., 1979).

- Fuel consumption, LE/h.

- Labor cost: The operator salary about $10 \mathrm{LE} / \mathrm{h}$

Total cost per hours (LE/hour) $=$

Fixed cost (LE/year) + Operating costs (LE/year) ----(9)

Production cost $(\mathrm{LE} / \mathrm{kg})=\frac{\text { total cost per hour } L E / h}{\text { productivity, } \mathrm{kg} / \mathrm{h}}$

\section{RESULTS AND DISCUSSION}

1. Effect of die speed, die holes' diameter, moisture content and adhesive materials on Productivity:

The results in fig. (2) showed the effect of die speed on pelleting machine productivity at different moisture contents of feed mixture using gelatin as adhesive material and die holes diameter $3 \mathrm{~mm}$.. The results showed that as general trend, as die speed increases from 85 to 190 r.pm., pelleting machine productivity increases for all die holes' diameters, all moisture contents and with or without adhesive materials in feed formula. Pelleting machine productivity increases from 26.72, 30.128, 33.008, 36.614 to $40.22 \mathrm{~kg} / \mathrm{h}$ and pelleting efficiency increases 
from $97.584 \%, 97.708 \%, 97.833 \%, 97.957 \%$ to $98.082 \%$ as die speed increases from $85,95,115,160$ to $190 \mathrm{rpm}$., respectively (at die holes' diameter $5 \mathrm{~mm}$, using gelatin as adhesive material and $28 \%$ moisture content). Machine productivity increases from 32.66, 37.58 to $40.22 \mathrm{~kg} / \mathrm{h}$ and pelleting efficiency decreases from $98.393 \%, 98.269 \%$ to $98.082 \%$ by increasing die holes' diameter from 3, 4 to $5 \mathrm{~mm}$, respectively (at 190 $\mathrm{rpm}$ die speed, $28 \%$ moisture content and using gelatin as adhesive material). At die speed $190 \mathrm{rpm}$ pelleting machine productivity increases from 40.078 to 40.22 $\mathrm{kg} / \mathrm{h}$. Also, pelleting efficiency increases from $97.217 \%$ to $98.082 \%$ by increasing moisture content from $25 \%$ to $28 \%$ then machine productivity and pelleting efficiency decreases to $36.372 \mathrm{~kg} / \mathrm{h}$ and to $97.530 \%$ at $31 \%$ moisture content for die holes' diameter $5 \mathrm{~mm}$ and using gelatin as adhesive material. For $28 \%$ moisture content, die holes' diameter $4 \mathrm{~mm}$ and die speed 190 $\mathrm{rpm}$, pelleting machine productivity increases from $24.26,31.1$ to $37.58 \mathrm{~kg} / \mathrm{h}$. Also pelleting efficiency increases from $97.833 \%, 98.020 \%$ to $98.269 \%$, respectively (using no adhesive material, using molasses $\&$ gelatin as adhesive materials respectively). The highest value of pelleting machine productivity was $40.22 \mathrm{~kg} / \mathrm{h}$ at die speed $190 \mathrm{rpm} ., 5 \mathrm{~mm}$ die holes' diameter and $28 \%$ moisture content of feed mixture with gelatin as adhesive material in feed formula.
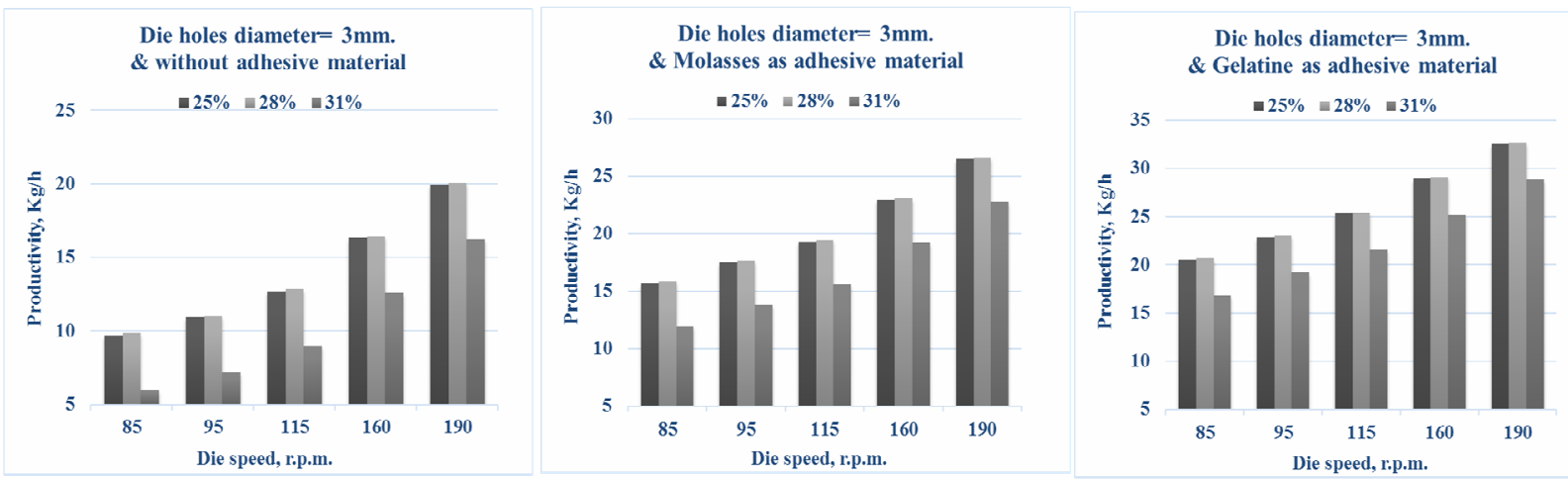

Fig. 2. Effect of die speed on pelleting machine productivity at different moisture contents of feed mixture using gelatin as adhesive material and die holes' diameter $3 \mathrm{~mm}$.

2. Effect of die speed, die holes' diameter, moisture content and adhesive materials on pellets durability:

The results in fig. (3) showed the effect of die speed on pellets durability at different moisture contents of feed mixture using gelatin as adhesive material at die holes' diameter $3 \mathrm{~mm}$. As general trend, pellets durability increases by increasing die speed \& increasing feed moisture content. It also, decreases by increasing die holes' diameter. the pellets durability increases by using adhesive material in feed formula compared to feed formula without adhesive material. Also, the pellets durability of using gelatin as adhesive material in feed formula is higher than using molasses. at die holes' diameter $5 \mathrm{~mm}$, using gelatin as adhesive material and $28 \%$ moisture content, the pellets durability increases from $90.2 \%, 91.52 \%, 94.78 \%$, $96.1 \%$ to $97.42 \%$ as die speed increase from 85,95 , 115,160 to $190 \mathrm{rpm}$. respectively. as die holes' diameters increase from 3 to $5 \mathrm{~mm}$, the pellets durability decreases from $99.480 \%, 98.480 \%$ to $97.420 \%$ by increasing die holes' diameter from 3,4 to $5 \mathrm{~mm}$ respectively (at $190 \mathrm{rpm}$ die speed, 28\% moisture content and using gelatin as adhesive material). at die speed $190 \mathrm{rpm}$ the pellets durability increases from $96.98 \%, 97.42 \%$ to $97.86 \%$ by increasing moisture content from $25 \%, 28 \%$ to $31 \%$ for die holes' diameter $5 \mathrm{~mm}$ and using gelatin as adhesive material. for $28 \%$ moisture content, die holes' diameter $4 \mathrm{~mm}$ and die speed $190 \mathrm{rpm}$, the pellets durability increases from $97.48 \%, 97.88 \%$ to $98.48 \%$ respectively (using no adhesive material, using molasses \& gelatin as adhesive materials respectively). The highest value of pellets durability was $99.92 \%$ at die speed $190 \mathrm{rpm}$., $3 \mathrm{~mm}$ die holes' diameter and 31\% moisture content of feed mixture with gelatin as adhesive material in feed formula.
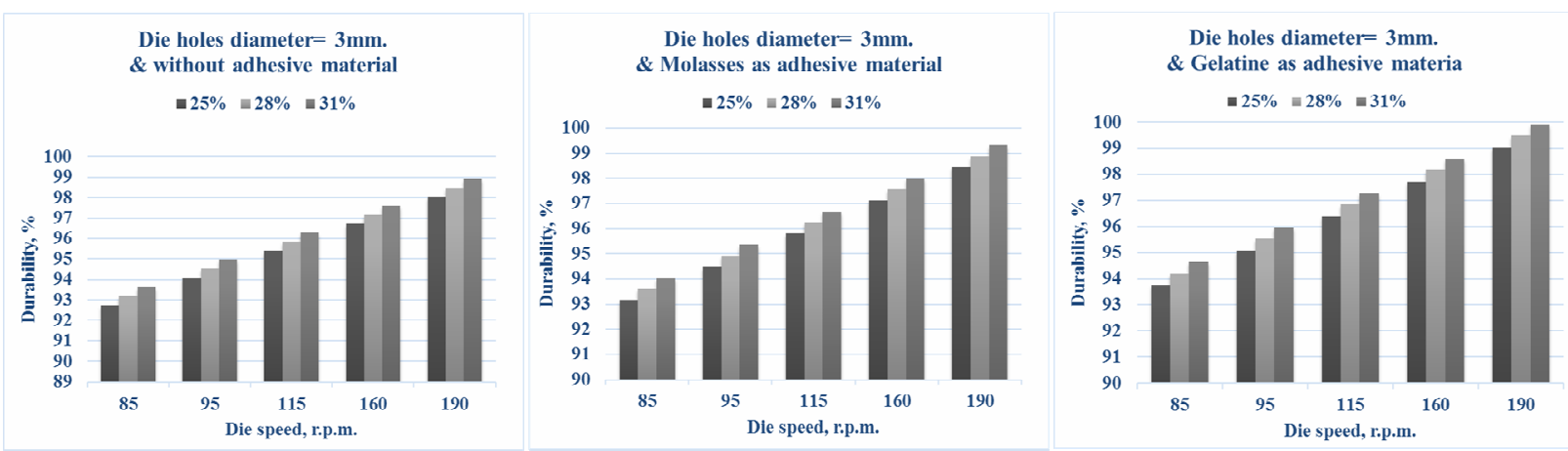

Fig. 3. Effect of die speed on pellets durability at different moisture contents of feed mixture using gelatin as adhesive material at die holes' diameter $3 \mathrm{~mm}$. 
3. Effect of die speed, die holes' diameter, moisture content, adhesive materials on specific consumption energy:

The results in fig. (4) showed the effect of die speed on specific consumption energy at different moisture contents of feed mixture using gelatin as adhesive material and die holes' diameter $3 \mathrm{~mm}$. As general trend, specific consumption energy decreases by increasing die speed \& increasing die holes' diameter. It also, increases by increasing moisture content of feed mixture. the specific consumption energy decreases by using adhesive material in feed formula compared to feed formula without adhesive material. Also, the specific consumption energy of using gelatin as adhesive material in feed formula is lower than using molasses. At die holes' diameter $5 \mathrm{~mm}$, using gelatin as adhesive material and $28 \%$ moisture content, the specific consumption energy decreases from 16.26, $15.85,15.77,15.39$ to $15.08 \mathrm{~kW} . \mathrm{h} /$ ton as die speed increase from $85,95,115,160$ to $190 \mathrm{rpm}$.
Respectively. As die holes' diameters increase from 3 to $5 \mathrm{~mm}$, the specific consumption energy decreases from $17.03,15.45$ to $15.08 \mathrm{~kW} . \mathrm{h} /$ ton by increasing die holes' diameter from 3, 4 to $5 \mathrm{~mm}$ respectively (at $190 \mathrm{rpm}$ die speed, 28\% moisture content and using gelatin as adhesive material). At die speed $190 \mathrm{rpm}$ the specific consumption energy increases from 14.78, 15.08 to $17.07 \mathrm{~kW} . \mathrm{h} /$ ton by increasing added moisture content from $25 \%, 28 \%$ to $31 \%$ for die holes' diameter $5 \mathrm{~mm}$ and using gelatin as adhesive material. For $28 \%$ added moisture content, die holes' diameter $4 \mathrm{~mm}$ and die speed $190 \mathrm{rpm}$, the specific consumption energy decreases from $28.66,20.75$ to $15.45 \mathrm{~kW} . \mathrm{h} / \mathrm{ton}$ respectively (using no adhesive material, using molasses \& gelatin as adhesive materials respectively). The lowest value of specific consumption energy was 15.08 $\mathrm{kW} . \mathrm{h} / \mathrm{ton}$ at die speed $190 \mathrm{rpm} ., 5 \mathrm{~mm}$ die holes' diameter and $28 \%$ moisture content of feed mixture with gelatin as adhesive material in feed formula.
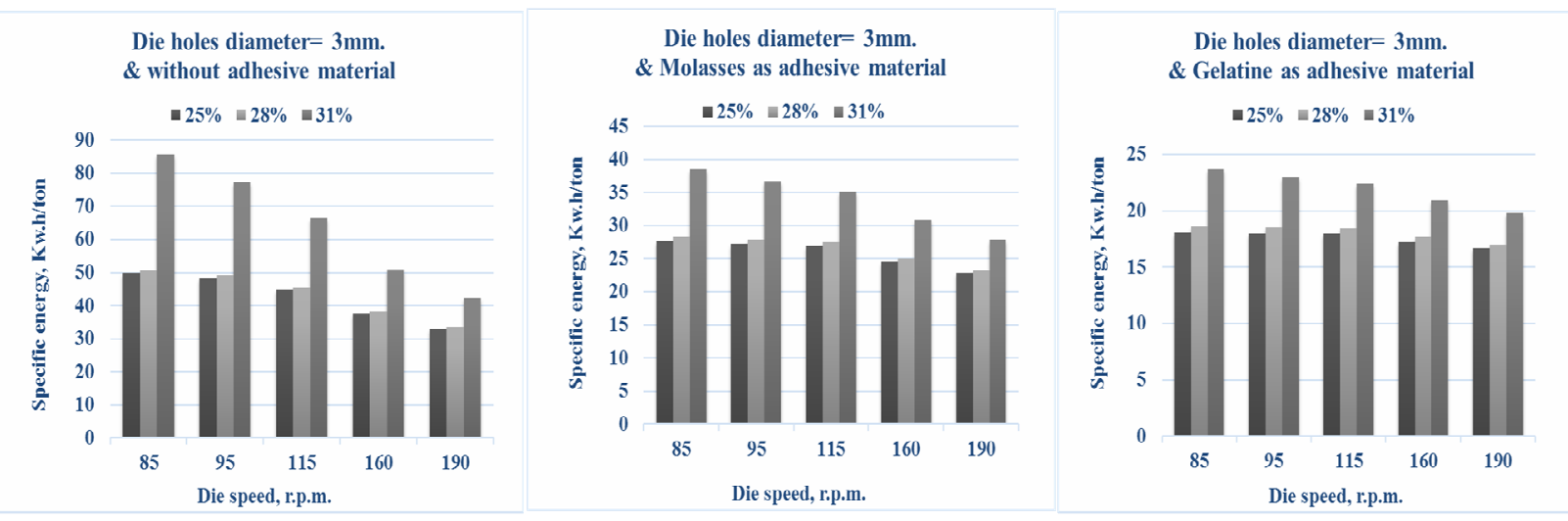

Fig. 4. Effect of die speed on specific consumption energy at different moisture contents of feed mixture using gelatin as adhesive material and die holes' diameter $3 \mathrm{~mm}$.

\section{Cost analysis:}

Figure 5 showed the production cost for pelleting machine using different die holes' diameter $(3,4 \& 5 \mathrm{~mm})$ at die speed 190 rpm., $28 \%$ moisture content of feed mixture, with gelatin as adhesive material in feed formula and powered with different sources of power: (220V., AC, on grid system - Diesel generator - 1, 5 \& 8 hours PV system). Production cost decreases by increasing die holes' diameter due to increasing machine productivity. Production cost was $0.048,0.042$ \& $0.039 \mathrm{LE} / \mathrm{kg}$ for die holes' diameters 3, 4 \&5 mm., respectively using $220 \mathrm{~V}$., AC, on grid as a source of power. Production cost was $0.087,0.075 \& 0.070 \mathrm{LE} / \mathrm{kg}$ for die holes' diameters 3, $4 \& 5 \mathrm{~mm}$., respectively using diesel generator as a source of power. Production cost was $0.061,0.053 \& 0.050 \mathrm{LE} / \mathrm{kg}$ for die holes' diameters 3, $4 \& 5 \mathrm{~mm}$., respectively using 1-hours PV system as a source of power. Production cost was $0.083,0.072 \&$ $0.068 \mathrm{LE} / \mathrm{kg}$ for die holes' diameters $3,4 \& 5 \mathrm{~mm}$, respectively using 5-hours PV system as a source of power. Production cost was $0.146,0.127 \& 0.118 \mathrm{LE} / \mathrm{kg}$ for die holes' diameters 3, $4 \& 5 \mathrm{~mm}$., respectively using 8-hours PV system as a source of power.

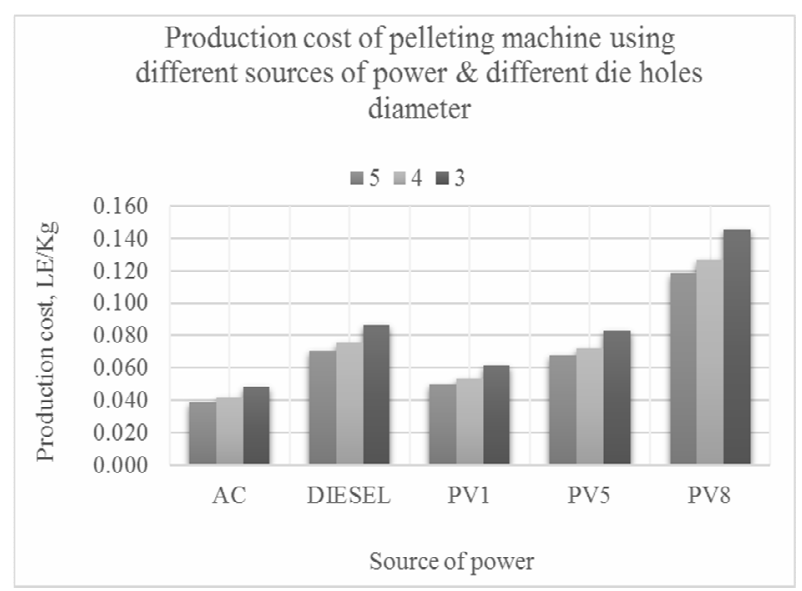

Figure 5. Production cost at different sources of power and different die holes' diameter $3,4 \& 5 \mathrm{~mm}$ at die speed $190 \mathrm{rpm} ., 28 \%$ moisture content of feed mixture and using gelatin as adhesive material in feed formula.

\section{CONCLUSION}

The highest value of pelleting machine productivity was $40.220 \mathrm{~kg} / \mathrm{h}$ at die speed $190 \mathrm{rpm}$., $5 \mathrm{~mm}$ die holes' 
diameter and $28 \%$ moisture content of feed mixture, with gelatin as adhesive material in feed formula and using $220 \mathrm{~V}$., AC, on grid as a source of power. At the same conditions, the pelleting efficiency was $98.082 \%$, pellets durability was $97.420 \%$, specific consumption energy was $15.08 \mathrm{~kW} . \mathrm{h} /$ ton and production cost was $0.039 \mathrm{LE} / \mathrm{kg}$.

\section{REFERENCES}

Abdel Wahab, M. K.; M. A. Tawfik; A. M. El shal and Y. A. El hussiny (2011). Factors affecting the performance of aquatic feeds flat die pelleting machine. Misr J. Agric. Eng., 28(1): 129-148.

ASAE (1996). American Society of Agricultural Engineers Standards, Engineering Practices, and Data, ASAE Standard Book.

Barger, E.L.; J.B. Lijedahl; W.M. Carleton and E.G. Mckibben (1979). Tractor and their power units. $2^{\text {nd }}$, John Wiley \& Sons, Inc., New York, USA. pp. 390-399.

David, A. F. (2003). Pelleting for profit-part. National grain and feed association. Feed and feeding digest. Vol. 54, No.6, November 13.

Fouda, T.; A. elmetwalli; O. kaddour and A. derbala (2015). Manufacturing and performance evaluation of a compatible unit to produce animal feed pellets. Economic engineering in agriculture and rural development., vol. 15.

Greer, D. and J. Fairchild (1999). Cold mash moisture control boosts pellet quality. Feed management. Vol. 50, No.6, Watt publishing company, 14t. Marris, 111.
Kaddour, U. and A. A. Elmetwalli (2015). Manufacturing and identifying the optimum operating parameters of a local pellet mill machine to produce aquatic feed. Misr J. Agric. Eng., 32(1) 87-104.

Kaliyan, N. and R. V. Morey (2009). Factors affecting the strength and durability of densified products. Biomass and Bioenergy, 33(3): 337359.

Kaul and Egbo (1985). Introduction to agriculture mechanization "Management and Cost Analysis" First Published, pp.172-175.

Susawa, K. (1978). Roughage wavering techniques in japan. JARQ, 12(1): 17-21, Tropical Agriculture Research Center, Japan.

Tabil, L. G. and S. Sokhansanj (1996). Compression and compaction behavior of alfalfa grinds. Part 1: compression behavior. Powder Handling and Processing 8(1).

Tumuluru, J. S.; wright, C. T., Hess, J. R.and kenney, K. L. (2011). A review of biomass densification systems to develop uniform feedstock commodities for bioenergy application. Biofuels bioprod. Biorefin. 5, 683-707.

Tumuluru, J. S. (2013). Effect of process variables on the density and durability of the pellets made from high moisture corn stover. Biosystems engineering 119: 44-57.

Tumuluru, J. S. (2015). High moisture corn stover pelleting in a flat die pellet mill fitted with a 6 mm die: physical properties and specific energy consumption. Energy science and engineering. 327-341.

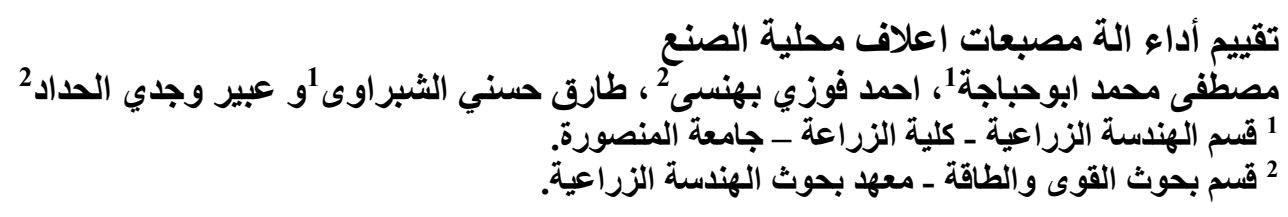

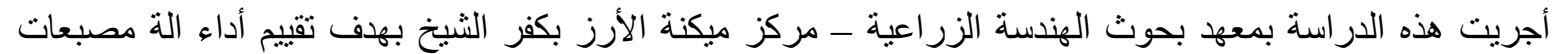

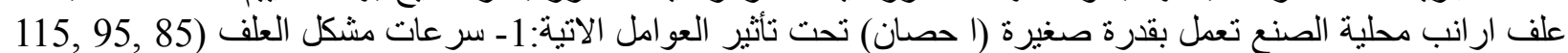

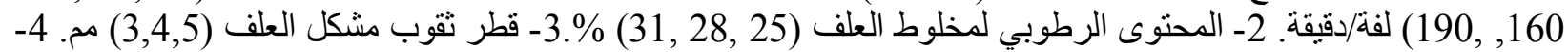

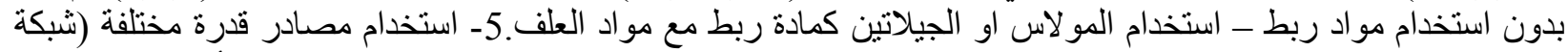

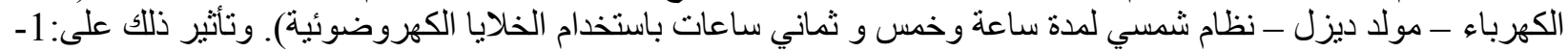

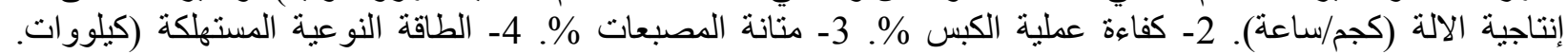

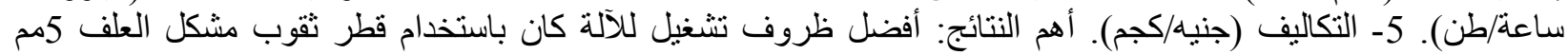

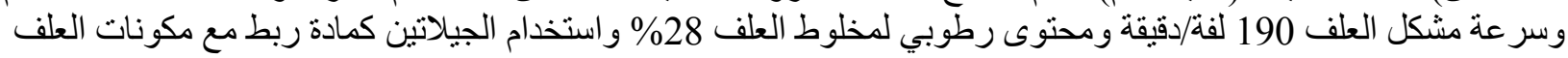

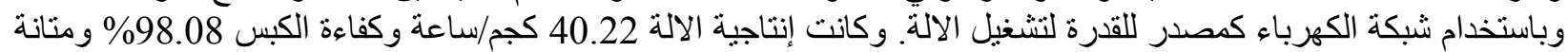
المصبعات 97.42\% و الطاقة النوعية المستهكة كانت 17.03 كيلووات. ساعة/طن وتكاليف الإنتاج 39 جنيه/طن. 